\title{
Género, economía familiar y seguridad alimentaria en Nicaragua: empoderamiento de la mujer rural, estudio de caso en Muy Muy
}

Alejandra López C.

\section{Resumen}

A partir del año 2007 en Nicaragua se instaura un nuevo periodo de gobierno y con nuevas políticas sociales .El objetivo de las nuevas políticas sociales es la optimización de la calidad de vida de las y los nicaragüense y su eje central, el desarrollo y bienestar social de los mismos.

Dentro de estas políticas, se encuentra la de Seguridad y soberanía Alimentaria que tiene como principal instrumento el Programa Productivo Alimentario (PPA), conocido también como Hambre cero. Una características particular de este programa es que sus beneficiarios directos son mujeres, principalmente habitantes del área rural de nuestro país.

Uno de los municipios en los que se implementó el Programa Productivo Alimentario (PPA), fue Muy Muy que pertenece al departamento de Matagalpa y es como la mayoría de ellos, netamente agrícola. A partir del 2008 que llega este programa, los habitantes de este lugar han experimentado procesos de empoderamiento que les permiten reconocerse como sujetos de poder, de manera individual y colectiva. Este trabajo busca analizar y documentar las experiencias sobre este tema.

El empoderamiento como tal circunscribe el tratamiento de elementos psicológicos, sociales, culturales y cognitivos. El grado de empoderamiento que alcancen las mujeres de esta comunidad depende -tal como se estudia-- del deseo, la voluntad y determinación personal de las mismas. Aunque no todo es color de rosa, hay sus obstáculos los cuales deben superarse.

Palabras Claves: Empoderamiento, Programa productivo alimentario, Muy Muy, Mujeres, Economía familiar.

\begin{abstract}
Since 2007, Nicaragua started a new period of government that brought new social policies with itself.The aim of the new social policies is to optimize life's quality Nicaraguans, and central axis is the development and social welfare of Nicaraguan citizens. Within these new policies there is a policy of food security and sovereignty that has as main instrument of action the Food Production Program, also known as "Hambre Cero".

A particular characteristic of this program is that women are direct beneficiaries, mainly people from rural areas of our country. Muy Muy has been one of the municipalities benefited with this program. Muy Muy is located in the department of Matagalpa and is a purely agricultural village. On this city, this policy has taken place since 2008 and since it started has allowed the population to begin an empowerment processes that permits them to be recognized as subjects of power.

Empowerment, circumscribes the treatment of social elements, cultural, cognitive and psychological. That is why the degree of empowerment that every woman of this community reaches, depends on the desire to excel, will and personal determination.
\end{abstract}

Keywords: Empowerment, food production program, Muy Muy, Women, Family economy. 


\section{Introducción}

Nicaragua en los últimos años ha sido escenario de diversas políticas sociales que pretenden beneficiar el desarrollo humano de las y los nicaragüense. En el 2007 el Gobierno de Reconciliación y Unidad Nacional (GRUN) delineó en el Plan Nacional de Desarrollo Humano (PNDH) sus principales políticas sociales y uno de los principios fundamentales que el modelo impulsa es la seguridad y soberanía alimentaria, cuyo principal instrumento de acción es el Programa Productivo Alimentario (PPA) que tiene por objetivos capitalizar, capacitar y organizar a las familias beneficiadas.

Un rasgo importante de este programa es el hecho de que las mujeres son las beneficiarias directas, de esta forma el programa pretende no sólo beneficiar la calidad de vida de las familias si no también transformar las relaciones de género y el liderazgo de la mujer rural. Conviene señalar que aunque el PPA es un programa que beneficia a las mujeres, desde el punto de vista material, pretende alcanzar empoderamiento, el cual está mediado por la capacidad de gestión a lo interno del hogar y por el emprendedurismo de las mismas.

Como objetivo principal de la investigación, se busca analizar el empoderamiento alcanzado por la mujer rural de Muy Muy a partir del Programa Productivo Alimentario (PPA). La justificación de esta temática tiene que ver con el deseo de conocer las apreciaciones de las beneficiarias sobre el impacto del PPA. Saber si las mujeres beneficiarias de verdad se sienten empoderadas por dicho programa y con ello estructurar una explicación propia del mismo, al margen de cualquier mediación.
Este trabajo procura responder cuatro aspectos teóricos fundamentales: Tener, Saber, Querer y Poder. Si bien, existe un considerable número de trabajos e investigaciones relacionados al Programa, son escasos aquellos enfocados al estudio metodológico del empoderamiento de la mujer, destacando entre estos los estudios realizados por el grupo Venancia ${ }^{1}$.

De igual manera, responde a una metodología cualitativa donde la acción indagatoria estará ligada a la interpretación de los hechos y datos no numéricos, permitiendo la profundización en las interioridades del fenómeno a estudiar .Así mismo esta investigación se sustenta en un diseño de campo basado en la recolección de datos directamente de los sujetos investigados (Observación participante) adoptando un nivel explicativo.

Por último, es importante destacar que para la recolección de datos y el análisis de información, se hizo uso de técnicas de las ciencias sociales, como la revisión y el análisis documental, registros anecdóticos, entrevista semi-estructurada, fichas de contenidos, grabaciones y fotografías. Las entrevistas estuvieron dirigidas principalmente a las beneficiarias directas del programa, las protagonistas habitantes de Muy Muy, así como a los técnicos y líderes de la comunidad.

\section{Características socioeconómicas de Muy Muy}

\section{Ubicación geográfica}

Según la ley de División Política Administrativa, el municipio de Muy Muy pertenece al departamento de Matagalpa. En relación a su fundación, un texto de la Alcaldía reseña; "aunque se desconoce la fecha

1 EL grupo Venancia nace en 1991 y es un Colectivo de mujeres que se dedica a la Educación y Comunicación Popular Feminista. Ubicado en Matagalpa ha sido parte del movimiento de mujeres de Nicaragua durante los últimos veinte años. Actualmente forman parte de la Red de Mujeres de Matagalpa, la Red de Mujeres del Norte Ana Lucila y la Red de Mujeres contra la Violencia. A nivel de Centroamérica forman parte de la Alianza Feminista Centroamericana por la Transformación de la Cultura Patriarcal. 
de su fundación, esta puede considerarse bastante remota ya que la pila bautismal de la parroquia fue fundada en el año de 1748" (Alcaldía de Muy Muy; ficha municipal, 2013).

Atendiendo al criterio de extensión territorial, el municipio de Muy Muy ocupa el quinto lugar entre los municipios del departamento y el primero en cuanto a antigüedad. Este cuenta con una cabecera municipal del mismo nombre, ubicada a 148 kilómetros al norte de Managua, con 11 Barrios y 12 Comarcas Rurales.

\section{Condición económica}

La actividad económica predominante de este municipio es la agricultura, la cual es fundamental para el consumo del mercado interno $y$ el autoconsumo familiar. La actividad agrícola es el segundo rubro de mayor importancia económica. En gran medida, la familia campesina se dedica a la siembra de granos básicos, tales como arroz, frijoles, musáceas y tubérculos.

Podría decirse que es una economía campesina de subsistencia (Ficha municipal) que a su vez descansa fuertemente en la producción ganadera de leche y engorde. Existen aproximadamente 25,000 cabezas de ganado vacuno, cuya comercialización, en su gran mayoría, se realiza en pie.

\section{Características socioeconómicas de la mujer rural}

A partir de la interacción con las protagonistas del PPA de Muy Muy establecimos los siguientes rasgos característicos de las mismas:

- Como toda mujer nicaragüense la de Muy Muy es trabajadora y dedicada a sus labores. Prevalece el patrón cultural tradicional de amas de casas consagradas al cuidado de los hijos y del hogar.

- La mayoría de las entrevistadas no están casadas con su cónyuge. Conviven en "unión de hecho estable". Mantienen una relación de subordinación y dependencia (sumisas) a la voz y/o criterios de su pareja.

- Son madres de más de tres hijos. Ellas se integran a la vida de pareja a edades tempranas.

- Tienen un nivel de escolaridad bajo. La mayoría no terminan la primaria. De las 17 entrevistadas sólo una tenía el octavo grado aprobado.

- Antes de la llegada del Programa (PPA), casi todas ellas dependían en materia económica a sus maridos, siendo su labor principal la de ser madres.

\section{Conceptos y elementos en el tratamiento del empoderamiento de la mujer}

La palabra empoderamiento viene del inglés empowerment y significa facultarse, habilitarse o autorizarse. "El Empoderamiento consiste de manera literal en el proceso a través del cual cada mujer se faculta, se habilita y se autoriza" (Lagarde: 2015; 5). Según el documento Vías para el empoderamiento de las mujeres de Marcela Lagarde, se llamará empoderamiento al proceso de transformación mediante el cual cada mujer deja de ser el objeto de otros y se convierte en sujeta de su propia vida. Una mujer se encuentra empoderada cuando tiene la capacidad de adquirir poder o autoridad de manera individual y colectiva.

En este ensayo se comprenderá el empoderamiento como el proceso mediante el cual la mujer se vuelve un ser para sí, un ser autónomo, con capacidad de decisión y se siente segura de sí misma, identifica sus capacidades y las potencializa. De tal modo que su vida es controlada por ella misma.

El empoderamiento es un camino de dos vías. Para lograrlo, el sujeto debe reconocerse con autoridad de manera individual y colectiva. En principio, el empoderamiento en un nivel individual está ligado a la definición 
personal, autoestima y a la manera en que esta se percibe como sujeto con poder sobre ${ }^{2}$ y poder $\mathrm{de}^{3}$.

Empoderamiento es sin duda un concepto con componentes cognitivos, psicológicos, económicos y políticos. "Todo desarrollo llega como resultado de un proceso de cambio guiado por varios factores" (Caubergs, 2007). Tomando como referencia la Guía metodológica del empoderamiento de la mujer, identificamos cuatro aspectos importantes en el proceso de empoderamiento de la mujer, como se señaló antes: tener, saber, querer y poder.

El tener (poder de) se refiere al "poder económico reforzado en términos de beneficios materiales" (Género e Indicadores; 2007). El "saber" pone de manifiesto la importancia de la aplicación de los conocimientos o la capacidad de traducir estos conocimientos en acciones y recursos. El tercer aspecto, "querer", tiene mucho que ver con la voluntad y el poder interior, así como con la toma de conciencia sobre el propio proyecto de vida. En el aspecto del "poder" confluyen los componentes anteriores, principalmente el tener y el querer, pues las protagonistas han de ser capaces de tomar decisiones, de asumir responsabilidades, de ser libre en sus actos y de utilizar recursos propios.

\section{Programa Productivo Alimentario (PPA)}

\section{Definición y objetivos}

El Programa Productivo Alimentario, es el instrumento más importante de la política de soberanía y seguridad alimentaria implementada por el Gobierno de Reconciliación y Unidad Nacional (GRUN) a partir del año 2007. Entre los objetivos principales del programa está, "erradicar el hambre, la desnutrición crónica así como disminuir la pobreza extrema y el desempleo en familias rurales pobres" 4 Este proceso se hará mediante el incremento cuantitativo y cualitativo de la producción y el consumo de alimentos proteicos. Este a la vez tiene tres objetivos específicos: capitalizar a las familias campesinas con un Bono Productivo Alimentario (BPA), capacitar a estas familias en aspectos sociales, administrativos $\mathrm{y}$ tecnológicos y organizarlas para que asuman el manejo de sus fondos rotativos.

\section{Antecedentes}

Antes de la llegada de PPA a Muy Muy en el año 2007, no había en este municipio un programa o proyecto similar que tuviera las mismas características, en cuanto a beneficio a las mujeres pobres del área urbana ni de habitantes de zonas rurales, marginadas del municipio .En agosto del 2008 se comenzaron las primeras entregas de los bonos productivos, correspondiendo un total de 150 bonos típicos para igual número de beneficiarios.

\section{Criterios de selección}

Los criterios de selección utilizados por los Gabinetes de familia son los mismos usado a nivel nacional:

- los beneficiarios deben de ser mujeres, de preferencia mujeres rurales.

- Toda mujer sujeta al programa, debe poseer de una a diez manzanas de tierra y no tener vacas, en el caso de recibir el bono típico.

- Deben ser de escasos recursos y habitantes de la comunidad

2 El «poder sobre»: esta noción está basada en las relaciones, de dominación, de subordinación. Supone que el poder sólo existe en cantidad limitada, es un poder que se ejerce sobre alguien o, de manera menos negativa, que permite "guiar al otro». Suscita resistencias que pueden ser pasivas o activas.

3 El "poder de»: comprende la capacidad de tomar decisiones, de tener autoridad, de solucionar los problemas y de desarrollar una cierta creatividad que haga a la persona apta para hacer cosas. La noción hace referencia, pues, a las capacidades intelectuales (saber y saber hacer) y a los medios económicos.

4 Dato obtenido de la entrevista realizada al delegado municipal de Muy Muy 


\section{Aplicación el PPA en Muy Muy}

Como se ha señalado, la selección de las personas beneficiadas está a cargo de los gabinetes de familias ${ }^{5}$. La verificación de que se cumplen las condiciones establecidas corre a cargo de la delegación de la promotoría solidaria de cada municipio o departamento. Luego se procede a la materialización de la entrega de los bienes a las mujeres.En Muy Muy el bono que mayormente se ha entregado es el bono típico consistente en la entrega de una vaca, una cerda reproductora y diez aves, así como materiales vegetativos y de tabulación.

Las mujeres beneficiadas por el programa se organizan en núcleos, conformando una junta directiva de cinco a seis personas; se apertura una cuenta bancaria de ahorro, donde se deben de depositar un $20 \%$ del costo del bono, como fondo revolvente. La agrupación de estas mujeres facilita las oportunidades de acceder a créditos, capacitaciones técnicas y financieras. El número de miembros en los núcleos dependerá del número de beneficiarias que haya en determinada comunidad ya que estos se instauran por sector. Un núcleo ha de tener como máximo 50 personas.

El complemento imprescindible de la entrega de los bienes es la capacitación técnica que se les brinda a las mujeres para lograr un mayor aprovechamiento de los mismos. Las nuevas protagonistas asumen un nuevo rol como mujeres productoras, recibiendo asesoría en tópicos como autoestima, higiene e igualdad de género.

En los inicios del programa habían 10 técnicos en el municipio, que cumplían con un plazo de 22 meses de asistencia técnica, visitaban los hogares de las beneficiadas una vez al mes a excepción de que fuera necesaria su visita en otra ocasión .Actualmente solo queda un técnico en el municipio y el acompañamiento técnico se da por medio de la promotoría.

La Promotoría "es la estrategia de sostenibilidad del programa que permite que las familias desarrollen capacidades y habilidades para la atención de los bienes entregados y fomentar la autoayuda" (MEFCCA). Las promotoras fueron beneficiarias del programa y surgen de una elección interna, donde las mismas protagonistas proponen a las personas que tengan cualidades para realizar esta actividad. Cada promotora atiende de 10 a 12 protagonistas. El programa no solo habilita protagonistas, también crea los espacios necesarios para que surjan lideresas femeninas dentro de la comunidad.

La tercera y última etapa de la implementación del programa es la creación de planes de negocios de los núcleos organizados. Estas iniciativas de negocios se ajustan a las realidades y particularidades de los núcleos y son trabajadas en consenso con las protagonistas. En Muy Muy una iniciativa gubernamental consistió en la creación de la cooperativa multisectorial de mujeres productoras de Muy Muy, conocida como "El Esfuerzo RL". Es un centro de destace y procesamiento de carne de cerdo donde participan un bueno número de mujeres beneficiarias del PPA.

Los indicadores de logros utilizados para medir los resultados del programa son:

- La satisfacción de las familias beneficiadas

- La reproducción y cuido de los bienes. Por ejemplo sobre la vaca que se entrega se tiene la expectativa de uno a dos partos por años y de la cerda dos a tres partos.

5 Los Gabinetes de la familia, la comunidad y la vida, se organizan con personas que habitan una comunidad, que deseen reflexionar y trabajar en conjunto por mejorar las condiciones de vida de la comunidad y por promover la consideración, la estima, la autoestima y el aprecio entre los demás habitantes. 


\section{El PPA y el empoderamiento de la mujer de Muy Muy}

\section{Proceso individual y subjetivo}

Según Deere y León (2002), “La propiedad de bienes económicos se relaciona con la capacidad de las mujeres de actuar de manera autónoma o de poder expresar su propio interés en las negociaciones que afectan su vida". Uno de los factores más importantes asociados al empoderamiento de la mujer es la disponibilidad de recurso. La entrega del bono típico y bono vaca facilita el proceso de empoderamiento en la mujer. El recibir bienes motiva a las mujeres a salir adelante dándole seguridad, significando una fuente de ingresos propios, y por sus características particulares, la posibilidad de un aumento en los mismos de manera gradual.

La señora Martha Cruz habitante de la comunidad el Chaperno explica lo que significó el disponer de fuentes de ingresos personales: "Para mí fue muy bueno cuando me lo dieron (refiriéndose al bono productivo) ya que todo lo que tenía era de mi compañero, yo dependía de él y donde el hombre manda uno no manda nada".

Antes de la puesta en marcha del programa del bono productivo, la mayoría de las mujeres no tenían bienes materiales o fuentes de ingresos personales, y tenían que pedir la autorización su compañero para tomar decisiones sobre los bienes o recursos del hogar. La señora Alejandra Alvarado de 42 años de edad nos decía "En aquel tiempo (tiempo del gobierno anterior) nosotras las mujeres no teníamos nada y ahora somos dueñas".

Ahora ellas tienen la potestad de decidir libremente sobre los bienes, e incluso tienen la oportunidad de formar un negocio propio, como expresaba una de las entrevistadas de la comunidad de Venecia "No hay como tener uno sus cosas propia ${ }^{6 "}$

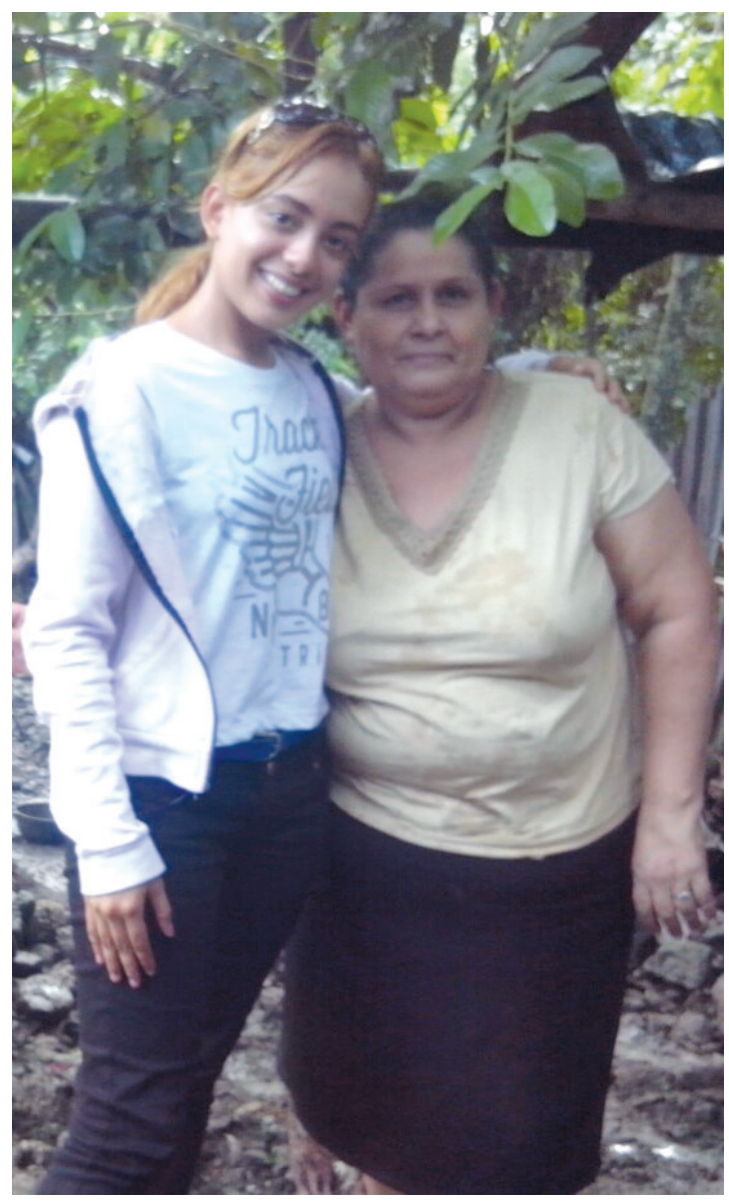

Dentro del aspecto del saber, referido a conocimientos o competencias prácticas e intelectuales (técnicas administrativas), las mujeres de Muy Muy pasaron por un proceso de capacitadas impartidos por técnicos o promotoras. Estos cursos han servido de apoyo para el ejercicio de una administración y control y fiscalización (mayordomía) con eficiencia de los recursos entregados.

Cuando la mujer posee bienes materiales y conocimientos administrativos es capaz de manejarlos con seguridad e independencia y es capaz de planificar sus acciones, puntualizar metas y trazar la vía idónea para la consecución de las mismas. Sobre este aspecto, doña Nubia Ruiz Zeledón de 40

6 Frase expresada por la señora Maritza del Socorro Zamora Cuba ,beneficiaria del PPA en el 2008 
años de edad nos decía lo siguiente: "Para mí me ayudo pues en que en el caso de la mujer nos sabiamos trabajar en el campo y ahora ya sabemos trabajar". Habitualmente el encargado de las actividades de producción del hogar es el hombre, pero tras la capacitación de las mujeres, ellas tienen la capacidad de integrase en las actividades antes mencionadas y aportar económicamente a su hogar.

Algo importante en este aspecto, es la libertad de toma de decisiones. Cuando la mujer tiene la seguridad de sus conocimientos, no espera la opinión o validación de sus decisiones por otro, confía en lo que hará y en sus argumentos para convertir su decisión en una acción transformadora de su propio medio.

Ejemplo de lo anterior, es el caso de la señora Maritza Del socorro Zamora de 26 años de edad que aparte de ser madre y esposa, todo los días se levanta a las cuatro de la madrugada a poner en práctica lo aprendido: cuida sus anímales y vela por su producción. Afirma que con su trabajo ha "levantado su casita". Sostiene como orgullo y autoridad, que a partir de que ella aporta al hogar con el trabajo adicional que hace, tiene más autoridad en la toma de decisiones, ya no depende del trabajo de su pareja para comprar zinc o para embaldosar su casa
Como se ha señalado arriba, el empoderamiento es un proceso que induce aspectos cognitivos y psicológicos. Este último hace referencia a la concepción $\mathrm{y}$ desarrollo de ideas y sentimientos que las mujeres pueden potenciar en la práctica en función de mejorar su condición de vida. El "Querer" es fundamental en el empoderamiento, pues el nivel que alcancen las mujeres está en dependencia del querer individual, propio .Aun con la existencia de recursos económicos y de formación académica, si el "querer" se encuentra ausente, el empoderamiento será difícil de alcanzar.

El trabajo de campo realizado en Muy Muy se constató que existen mujeres que maximizaron la utilidad de los bienes que se les entregaron, demostrando que deseaban mejorar su condición de vida. Este es el caso de la señora Carmen Ortega, de 50 años de edad, madre soltera de una niña de 10 años de edad que padece espina bífida e hidrocefalia y un joven estudiante de la escuela normal de Managua. Ella fue beneficiada con el bono patio y a partir de este recurso, obtiene ingresos que le proporcionan una mayor facilidad de llevar a su hija a rehabilitación sicomotora a la capital y costear los gastos de la formación académica de su hijo.

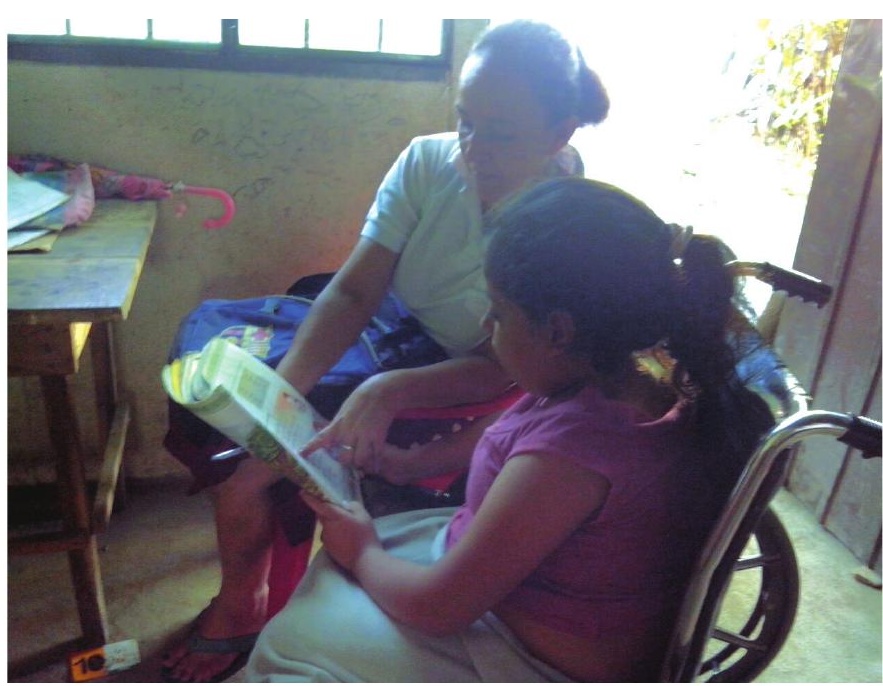


Si bien doña Carmen Ortega, no se dedica únicamente a reproducir animales, el hecho de haber sido favorecida, trajo un beneficio adicional: mayor estabilidad económica y emocional. La crianza, engorde y venta de cerdos le permite tener una nueva forma de enfrentar las incertidumbres de la vida. Ella no convive con ningún hombre, pero tiene voluntad y "quiere" salir adelante, impulsada por el aliciente de sus hijos y no piensa detener sus actividades de producción.

En relación a lo psicológico, es importante destacar la autoconfianza que la mujer tenga en sí misma, en cuanto al logro del éxito con sus esfuerzos de cambio una vez que se lo proponga. En esta reflexión es esencial la autoestima, la auto-confianza y el reconocimiento de aptitudes y capacidades propias.

La socióloga estadounidense Margaret Shuler (1997) señala que, "los derechos de las mujeres son derechos humanos: La agenda internacional del empoderamiento", reafirmando que, "para empoderarse es necesario reconocer los obstáculos mentales y económicos que dificultan el cambio" (Citado por De león. 1997; 190). En Muy Muy la mayoría de las mujeres reconocen que antes de la llegada del bono eran "mantenidas", o en otras palabras, que dependían económicamente de su marido, por tanto sujetas a la decisión de ellos. Las mujeres en su mayoría están cociente de su situación y reconocen cambios a partir de que ellas son mujeres autosuficientes económicamente hablando. La entrevistada, señora Johana Martínez, cuando se le preguntó por sus expectativas respondió: "seguir adelante, seguir aumentado mis animales, por qué antes ni gato tenía".

El empoderamiento hace referencia a poder, en este sentido al control de recursos materiales, a la capacidad de decidir y asumir responsabilidades. Una de las características de las mujeres de Muy Muy -ya mencionada-es su disposición al trabajo y asumir retos y nuevas responsabilidades. Algunas voces críticas sugieren que estos programas lo que ha hecho es darle una mayor carga de trabajo a las mujeres. Pese a ello, las entrevistada para este trabajo manifestaron sentirse contentas con las labores que les asigno el bono productivo.

\section{Autoafirmación y dignificación de la mujer}

Nathaniel Branden (1995) autor del libro "Los seis pilares del autoestima" señala que la autoafirmación es "simplemente la disposición de valerse por sí mismo, ser quien es abiertamente, tratarse con respecto en todas las relaciones humanas" (pág.: 36) La mujer tiene las mismas capacidades de trabajo que el hombre, el hecho de que la mujer tenga un nuevo papel como productora le facilita emanciparse del sentimiento de mismidad a partir de la función maternal o ama de casa. Las mujeres de Muy Muy ahora experimentan un sentimiento de libertad, se sienten más seguras y sin ataduras para compartir los cambios tras ser beneficiarias del PPA.

Cuando la mujer no posee recursos de subsistencia, le cuesta romper una relación de pareja crítica (en crisis), por el miedo de perder los recursos que le provee su compañero. Tiene miedo a enfrentarse a la vida sola y sin nada, situación que es distinta cuando poseer recursos o fuentes de ingreso Esta nuevo condición económica, aunque no es automática, le permite dejar de ser un sujeto condicionado y tener la libertad de romper una relación incómoda, y continuar sin que merme su calidad de vida, las posibilidades de mejora se incrementan.

En cuanto a la dignidad .Digno es alguien que se comporta con responsabilidad, seriedad y que inspira respeto (2008, Diccionario Larousse ilustrado) .La mujer al ser integrada en las actividades de producción, obtiene un medio para su autoafirmación y dignificación, en el sentido que, tanto la posesión de bienes como su imagen externa a la familia nuclear, le granjea respeto al gestionar recursos para sus proyecto. 


\section{De lo individual a lo colectivo}

Sororidad. Esta condición de asociación entre mujeres propicia la confianza, el reciproco reconocimiento de autoridad y el apoyo entre las mujeres. Experiencia que conduce a la mujer al encuentro de las relaciones positivas y la alianza existencial cuerpo a cuerpo, subjetividad a subjetividad permitiendo luchar juntas contra toda forma de opresión y así lograr el empoderamiento necesario en el proceso de autoafirmación.

La antropóloga social Kate Young, citada por De Léon (1997) señalaba que "el potencial transformador de las necesidades practicas del empoderamiento necesita integrar a las personas oprimidas en el proceso de toma de decisión con el fin de identificar su necesidades y sus limitantes" (pág.190). En este sentido, es importante que la mujer, quien lleva un proceso individual de empoderamiento, se integre en un colectivo donde pueda relacionar su experiencia personal con la de otras mujeres, al mismo tiempo que valora los logros alcanzado durante el tiempo que está incorporada en el grupo.

La inserción de la mujer en colectivos le permite identificar sus debilidades y fortalezas. El trabajo en equipo le posibilita compartir sus obligaciones y aspiraciones, disfrutando en compañía los avances y logros alcanzados en lo material y espiritual, como producto de su nueva condición económica y de la interacción diaria con sus compañeras (Comisión de Mujeres y Desarrollo; 2007:36). Formar núcleos es una estrategia que hacer sentir a la mujer acompañada, se cerciora de que hay mujeres en sus mismas circunstancias apoyándola. Mientras se realizaba este trabajo de investigación se encontró un dato interesante: dos de las protagonistas de la comunidad de Venecia cuyas casa estaban contiguas, se levantaban juntas por la madrugada y entre las dos cuidaban y ordeñaban a sus vacas. Ellas contaban esta experiencia: "No trabajo sola trabajo con otra compañera" (Entrevista Realizada a la señora
Maritza del Socorro, habitante de Venecia; 19 junio 2015).

La formación de la cooperativa multisectorial de mujeres productoras de Muy Muy “El Esfuerzo RL" y la incorporación al programa de algunas de las beneficiarias han sido muy conveniente, ya que ellas se reconocen sujetos útiles, productivos y capaces dentro de este colectivo. Según la UNESCO, el establecimiento de cooperativas de mujeres, puede ser una estrategia válida para que las mujeres establezcan sus propias empresas, teniendo en cuenta sus necesidades y su contexto socioeconómico. Organizadas las productoras tienen mayor poder de negociación, son capaces de obtener un mayor número de insumos, así como de capacidad de comercialización de sus productos.

Las relaciones familiares. El hecho de que la mujer reciba ingresos económicos tienes efectos positivos y significativos en cuanto a su interacción dentro del hogar. El aportar dinero y el sentir que no depende más de su esposo le da mayor poder de decisión. Las investigaciones del grupo Venancia señalan que el PPA refuerza los roles de trabajo, esta afirmación se distancia en alguna medida de los hallazgos de este trabajo. En muchos casos, el compañero de la beneficiaria trabaja al lado de ella, sus familiares la apoyan. Esta condición es positiva ya que brinda más armonía en el hogar y al tener la mujer como acompañante a un pilar importante de socialización dentro del núcleo familiar (su compañero), se da un proceso de cambio -quizás lento en algunos casos-en este último, como sujeto de poder.

\section{Tierra, negociación y empoderamiento}

Algo que no fue señalado por las investigaciones anteriores, es la adquisición de tierras por parte de las mujeres de Muy Muy haciendo uso de sus nuevos ingresos. Estas investigaciones hacen énfasis en la falta de acceso a la tierra como una de las 
principales deficiencias del programa .Las mujeres entrevistadas durante el trabajo de campo para esta investigación, no manifestaron problemas con el acceso a la tierra, más bien dijeron que están comprando tierra para sembrar o criar a sus animales.

A partir de la venta de sus animales las mujeres compran tierras. Algunas de ellas le han comprado tierras a sus esposos, como es el caso de la señora Francisca Barrera Ortiz y la señora Maritza del socorro. Esta última le dijo a su esposo: "Si no me vendes vos la tierra, se la compró a otro" (Entrevista realizada el 19 de junio del 2015). El hecho de que las mujeres sean dueñas de propiedades fortalece no solo el poder de decisión si no el de negociación, precondición para se establezcan nuevas relaciones de pareja distribuyendo el poder tanto dentro del hogar como en las relaciones externas (fuera del hogar).

Al darse el proceso de adquisición de propiedades, tierras, entre las mujeres, se dan condiciones para establecer negociación entre iguales (propietarios -propietarias) en sus hogares. Siguiendo a Agarwal, (1994) puede decirse que las relaciones en el hogar se caracterizan por condiciones de cooperación como de conflicto, pues, "Los miembros de un hogar cooperan en la medida en que los arreglos de cooperación les dan a cada uno de ellos más beneficios que la no cooperación" (Citado por De león. 2008; pág. 300). El hecho de cooperar o aportar tiene el ingrediente de "decidir" o "influir", y eso no es extraño entre las familias campesinas donde se conserva la idea de que si no aporto nada, no puedo reclamar mucho. Una de las señoras entrevistadas sentenciaba: "donde manda él, no manda uno" (Nubia Ruiz Zeledón: entrevista realizada de 19 de junio del 2015)

La posesión de bienes y de tierras y animales, no solo le da a la mujer la posibilidad de ser sujeto de negociación dentro del hogar, sino también con personas ajenas a su familia. La tenencia de estos recursos redunda en el fortalecimiento de su autoridad confiriéndole poder de decisión, y con ello, relaciones más horizontales.

\section{Familia, género y economía doméstica: estrategias de cambio}

La seguridad alimentaria, la economía familiar campesina y el tema de género tienen una estrecha relación. Primeramente conviene señalar que los roles en cuanto a las labores de producción en el campo están distribuidos según el género. El hombre tiene un papel central dentro de la producción de alimentos para el hogar y la mujer es reducida a la administración y distribución de los recursos con que se cuentan, escasos en muchas ocasiones, para suplir las necesidades básicas.

La ley de seguridad alimentaria en Nicaragua, reconoce a la mujer como un pilar fundamental del hogar, cuya incorporación y participación en las actividades productivas representan un beneficio, tanto para ellas como para sus familias. Una muestra de esta aseveración y la intención que el espíritu de la ley promueve, es que el PPA tiene como enfoque central a la familia, confiriéndole a la mujer del hogar, un papel protagónico, al colocarla como albacea de los bienes, por su condición histórica de "mejor administradora del hogar".

La familia es el principal agente de socialización y como toda sistema organizado posee roles institucionalizados ${ }^{7}$, regidos por la expectativa (donde confluyen costumbres y/o tradiciones) de sus miembros y no por preferencias personales .La madre juega un papel fundamental dentro de la familia, puesto que es quien más tiempo comparte

7 Serie de expectativas de comportamiento que limitan la libertad de opción de una persona. 
con los hijos, siendo la encargada de la distribución de las tareas del hogar entre sus miembros.

Los hijos van conociendo el mundo en que viven a partir de su interacción con otra personas, pero su primer contacto es la familia .Cuando ellos crecen, por lo general repiten los patrones de conductas y roles de sus padres. Si es una joven que siempre vio a su madre cuidando de sus hermanos, cocinando, atendiendo al marido y acatando de manera sumisa las decisiones de su padre, entonces considerará normal desempeñar únicamente estas funciones.

Cuando la mujer produce ingreso y es dueña de bienes, la figura de "ama de casa" cambia dentro del seno de la familia. Al tener mayor participación en la toma de decisiones se fortalece la autoridad de la mujer en relación al varón (el esposo). Se produce una erosión que a corto o mediano plazo, generaría cambios en los roles tradicionales asignados en su núcleo (de reproductora y administrativa del hogar) abriendo el camino para que sus hijas e hijos, tengan otra actitud en el hogar y colaboren en la distribución de las labores y las relaciones de género sean más racionalizadas.

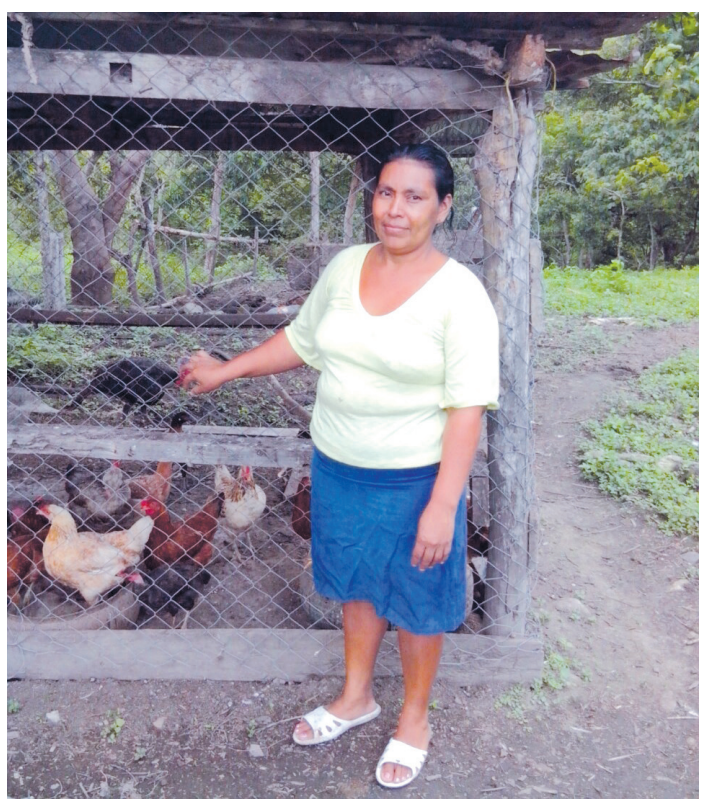

\section{Consideraciones finales}

El Programa Productivo Alimentario (PPA), principal instrumento de la política de seguridad y soberanía alimentaria y nutricional está contribuyendo al empoderamiento de la mujer rural del municipio de Muy Muy. El trabajo de campo y los resultados de esta investigación, sugieren que las mujeres han sido integradas en procesos de empoderamientos a nivel individual y colectivo.

El proceso en su etapa individual, destaca que han adquirido bienes materiales y herramientas de conocimientos que les permiten multiplicarlos y efectuar una mayordomía, eficaz y productiva de los mismos. Condición que en la mujer le permite establecer nuevas relaciones de poder tanto dentro del hogar como fuera de él. De igual forma, el programa motiva a la mujer a incorporase de manera activa y dinámica en las actividades productivas de su comunidad.

Colectivamente, el proceso de empoderamiento se evidencia en las relaciones de iguales y familiares, donde la mujer ya no se siente dependiente del hombre, pues ahora sus aportes económicos y materiales al hogar, son más significativos. Estos cambios que se vienen dando a lo interno de los hogares rurales, le ha dado confianza y capacidad a estas protagonistas, para que incidan en los procesos de cambio cultural dentro de los colectivos en el municipio.

Aunque las mujeres describen este programa como "muy bueno" hay aspectos que pueden fortalecerse, con el fin de que su incidencia en las familias y en el proceso de liderazgo de la mujer sea aún mayor .En principio debe de prestarse mucha atención a los procesos de selección de las beneficiadas, cumpliendo los criterios establecidos institucionalmente, y evitando que las inclinaciones o prejuicios 
partidarios, afecten la buena marcha del mismo.

A manera de sugerencia, las etapas de aplicación del o los programas sean organizados de tal forma que la etapa de capacitación vaya de primera a la etapa de entrega. Podría ser más factible que las mujeres primeramente fueran capacitadas técnicamente y luego capitalizadas con los bienes.

Consideramos también que dentro de la capacitación debería incluirse un proceso de sensibilización y ayuda psicológica. La razón es que con ellos se estimularían las capacidades cognitivas y de auto estima de la mujer, para que fortalezcan su conciencia y certeza del proceso al que se integraran.

\section{Referencias bibliográficas}

Asamblea Nacional de la República de Nicaragua. (2009). Ley de seguridad y soberanía alimentaria nutricional.

Arraigada, Irma (2006). “Dimensiones de la pobreza y políticas desde una Perspectiva de género". Revista CEPAL, 85.

Cacique, I. (2010). Factores de empoderamiento y protección de las mujeres contra la Violencia. Revista Mexicana de Sociología, 72, 37-71.

Castro Olivares, M. \& Palacio Rivas, R. (2006). La labor de apoyo Psicosocial en un programa para la superación de la extrema pobreza: La mirada de los promotores sociales del programa puente (Tesis para optar al título de Psicólogo, universidad de Chile, Facultad de ciencias sociales).

Comisión de Mujeres y Desarrollo. (2007) El proceso de empoderamiento de las mujeres. Guía metodológica. S. 1.: Grupo Género e Indicadores.

De León. (1997). Poder y empoderamiento de las mujeres. Revista Región y Sociedad, 11, 189-197.
Dirección General de Política agropecuaria y forestal. (2009). Política de seguridad y soberanía alimentaria nutricional.

García Rocha, Claudia (2009). Las Voces de "Hambre Cero". Instituto de Estudios Estratégicos y Políticas Públicas (IEEPP), Managua.

IDRC Y Instituto de estudios Peruanos Programas de transferencia Condicionadas e inclusión financiera: Oportunidades y Desafíos en América Latina (2011).Mayo 2011 Bogotá Colombia.

Kester, Paul. (2009). Informe evaluativo (2007-2008) / Programa Productivo Alimentario (PPA) "Hambre Cero". Managua: Embajada del Reino de los Países Bajos.

Larousse (2008). El pequeño Larousse Ilustrado (Edición no. 14). México.

Larracoechea Bohigas, E. (2011). ¿Ciudadanía Cero? El Hambre Cero y el empoderamiento de las mujeres. Los casos de Matiguás, Muy Muy y Río Blanco. Matagalpa: Grupo Venancia.

Larracoechea Bohigas, E. (2014). Hambre Cero cuatro años después .Cómo les ha ido a mujeres de Matiguás, Muy Muy y Río Blanco en Matagalpa. Matagalpa: Grupo Venancia.

Nathaniel, B. (1995). Los seis pilares de la autoestima. (Traducido por Vigil Rubio.). Barcelona: Paidós Ibérica. (Original publicado en 1994)

Quirós, A. (2011). Hambre Cero: Avances y Desafíos. Tercer Informe de Evaluación del Programa Productivo Agropecuario Hambre Cero. Managua: IEEP.

Schejtman, A. (2006).Seguridad, sistemas y políticas alimentarias en Centroamérica .Elementos para una estrategia integral de seguridad Alimentaria" .RIMISP, 4.

Téllez Infantes, A. Martínez Guirao, J. (2008) Sexualidad, Genero, Cambios de Roles y Nuevos modelos de familia. España: Seminario interdisciplinar de estudios de género del vicerrectorado de estudiantes y extensión universitaria 
de la universidad Miguel Hernández.

\section{WEBGRAFÍA}

MEFCCA. s/f. Programa Hambre Cero. http://www.economiafamiliar. gob.ni/index.php?option $=$ com content\&view $=$ article\&id=672\&Itemid $=228$.

De león, M. (2088) El poder de negociación y el proceso de empoderamiento En: Irene Cacique (2008) Estudios sobre cultura, género y violencia contra las mujeres. Consultado el 10 de junio del 2015

http:/ / biblioteca.clacso.edu.ar/Mexico/ crimuna m / 20100329121733 / Estudiossobreculturagenero.pdf

\section{Profe revise esta Bibliografía}

Montenegro, S. (2002). Las claves del empoderamiento sistematización de 100 años de experiencia. Consultado el día 5 de junio de 2015. http:// www.mugarikgabe.org/wp-content/ uploads/2015/05/EmpoderamientoXOCHILT-ACATL-1.pdf

Lagarde, M. Vías para el empoderamiento de las mujeres. Proyecto Equal I.O. Metal. Consultado el 5 de junio del 2015

http: / / www.femeval.es / proyectos / Proy e c tos A n t e ri ores / Sinnovaciontecnologia/Documents/ ACCION 3 _ c u a d e rno 1 . pdf. Consgultado 